\title{
Test and Determine the Strength of Ferrule Joint Pipe Fitting
}

\author{
S. Thirumavalavan, Sabarish R, Karthikeyan. S
}

\begin{abstract}
The tube connections in the cooling system are joints where a sleeve is crimped on the tube and then the tube is fitted between a nut and connector to ensure a leak proof joint. Earlier the crimping was done manually but the joints leaked in the field. A hydraulic tool is now available for crimping. The ability of the joint to prevent leakage depends on how well the sleeve 'bites' in the tube and how well the tube retains its original shape after crimping. These in turn depend on the (i) Material of the tube (ii) Material of the sleeve. Difference between the hardness of the sleeve and tube (with the sleeve being harder than the tube) Crimping pressure. Change in these parameters leads to different depth and amount of 'bite' and the extent to which the tube retains its original shape. A measure of the strength of the crimped joint is the amount of axial force needed to 'Pull Out' the sleeve after it has been crimped onto the tube. To create a variety of crimped joints where the parameters were varied. The size of the tube and thus that of the sleeve was not varied in order not to introduce additional variance in the parameters.

A test set up to be created to hold a tube with both ends having a crimped joint in a tensile testing machine.
\end{abstract}

Keywords : Hydraulic tool, Hardness, Crimped joints

\section{INTRODUCTION}

Gear box is the primary component which connects the rotor from the hub of a wind turbine to the generator and the gear box helps in increasing the speed (RPM) and decreasing the torque and greater speed of the shaft will help in large scale production of electricity. Formatter will need to create these components, incorporating the applicable criteria that follow[1],[3],[5].

Operational experience uncovers that the gearboxes of present day electrical utility breeze turbines at the MW level of appraised power are their weakest connection in the chain part. Little wind turbines at the $\mathrm{kW}$ level of evaluated power needn't bother with the utilization of gearboxes since their rotors pivot at a speed that is essentially bigger than utility level turbines and can be legitimately coupled to their electrical generators.

The power from the turn of the breeze turbine rotor is moved to the generator through the power train, for example through the fundamental shaft, the gearbox and the fast shaft. The run of the mill plan lifetime of an utility breeze turbine is

Revised Manuscript Received on August 22, 2019.

S. Thirumavalavan, Department of Mechanical Engineering, Bharath Institute of Higher Education and Research, Chennai, Tamilnadu, India. Email: thiru_thiru@hotmail.com

Sabarish R, Department of Mechanical Engineering, Bharath Institute of Higher Education and Research, Chennai, Tamilnadu, India. Email: sabarish5041@gmail.com

Karthikeyan. S, Department of Mechanical Engineering, Bharath Institute of Higher Education and Research, Chennai, Tamilnadu, India. Email: karthi.keyan5@yahoo.co.in
20 years, however the gearboxes, which convert the rotor cutting edges rotational speed of somewhere in the range of 5

and $22 \mathrm{rpm}$ to the generator-required rotational speed of around 1,000 to $1,600 \mathrm{rpm}$, ordinarily bomb inside an operational time of 5 years, and must be supplanted. That 20year lifetime objective is itself a decrease from a prior multi year lifetime structure objective.

The weakest connection of an utility size breeze turbine has been their gearbox. As turbine sizes expanded, the structure of gearboxes ready to deal with the torque produced by longer and heavier cutting edges has turned into an issue. What's more, turbine stacking is variable and difficult to foresee. Some gearboxes have bombed in under two years of activity. A large portion of these disappointments have been ascribed to the development of the machine undercarriage, which causes misalignment of the gearbox with the generator shafts and prompts disappointment. Such disappointment happens in the rapid back equipping bit of the gearbox when the orientation become broken. Standard turbine realignments can lessen the recurrence of disappointment, yet don't block their event[2],[4],[6].

\section{CLASSIFICATION OF WT GEARBOXES}

Wind Turbine Gearboxes can be classified as follows

- Depending upon the intensity of generator

- Depending upon the recurrence of power produced $50 \mathrm{~Hz}$ or $60 \mathrm{~Hz}$

- Depending upon the powers and minutes taken by the gearbox

- Depending upon the suspension framework utilized for principle shaft in nacelle

To comprehend gearboxes and the powers following up on the gearboxes, we have to comprehend the suspension frameworks which have been clarified underneath.

\section{A. Point Suspension}

The gearboxes for traditional 3-point suspension wind turbine structures work as the subsequent help purpose of the rotor shaft. In this way, the planet bearer, the planet transporter direction and the torque arm have been dimensioned to convey these additional heaps. It comprises of a long shaft with isolated orientation, gearbox bolstered by the pole with torque limitations.

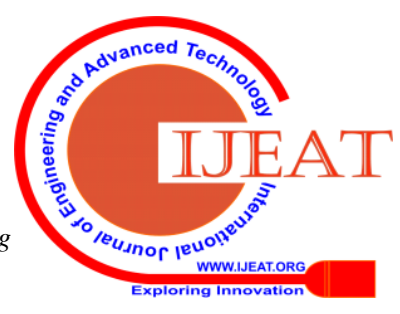




\section{B. Point Suspension}

Four-point-suspension (otherwise called twofold rotor suspension or isolated structure) is described by a primary shaft suspension, which comprises of one energy bearing or two isolated fundamental heading (see top picture). Weight powers just as yawing and gesturing minutes from the rotor are totally moved to the primary edge by the fundamental bearing system. For traditional breeze turbines with 4-point suspension with a demonstrated structure topology highlighting a mix of 1-2 planetary stages and 1-2 parallel or helical apparatus stages. It comprises of a back bearing which is coordinated into the gearbox with the gearbox foot-mounted on the bed plate. The front bearing is coordinated in the heap conveying structure of the nacelle[7],[9],[11].

\section{Rotor Side Integrated}

The current incorporated rotor side arrangements expand upon the qualities of the bogie rule in the principal planetary stage. The bogie guideline can make up for disfigurements in the encompassing structures accordingly guaranteeing ideal rigging load circulation.

\section{Generator Side Integrated}

ZF Wind Power is one of the business chiefs with regards to incorporated medium speed drives for wind turbines, with the model of our medium speed gearbox previously presented in 2009.

The glass fiber fabric is taken and cut into explicit measurements and with appropriate direction. The required number of layers for getting the all out thickness can be controlled by considering the tangle thickness and the glass-to-pitch proportion by weight[8],[10],[12].

The glass filaments are gauged and the tar is taken as 1:1 proportion by the heaviness of the fiber. At that point hardener is included by $10 \%$ of the heaviness of the tar or fiber. The gum and hardener are totally blended which structures the framework.

\section{COMPONENTS OF WT GEARBOXES}

Gearbox is a complete assembly of gears, shafts, bearings, housings, seals, heat sink, lubrication system and other associated components. These components have their own function and importance. Every component has to be designed with perfection to meet their purpose. These components are made from different material and undergo different manufacturing process (i.e. casting, milling, turning, hobbing and heat treatment etc) depending upon the requirement.

Components of the gearbox are listed below according to the plant layout. Their manufacturing and designing parameters will be as well discussed which helps in understanding their application[13],[15],[17].

List of components in a Gearbox

$\square$ Manufactured Components

\section{Casted Components}

- Housing

- Planet Carrier (Fig 1.6)

- Torque Arm

Forged Components

- Gears

Ring Wheel (Annulus)

Planet Wheel

Low Speed Shaft Wheel

Intermediate Speed Shaft Wheel

Sun Shaft

Pinion Shaft

Intermediate Speed Shaft

Planet shaft

Hollow Shaft

Torque arm Support Shaft

Bought out Components

Electrical Pump

Mechanical Pump

Heat Sink

Energy tube

\section{GEARBOXES LUBRICATION SYSTEM}

It is highly critical for the Wind turbine gearboxes to have the proper lubrication system in order to handle higher loads by the gearbox. Main lubrication supply to the gearbox is supplied through the Main manifold. Function of the manifold is to distribute the oil to the individual lubrication points through different branches[14],[16],[18]. Also the manifold takes care of the oil supply priority among the various positions. Below figure shows the skeleton set up of the internal a well as external lubrication channel tubes of the gearbox.

\section{RESULTS}

Ferrule is an integral part of coupling which is used in pipe fitting assemblies. Ferrule has a cutting edge which crimps / bites the Outer surface of tube during tightening. Crimped Ferrule does not allow the tube to come out of coupling and thus avoids oil leakage. Below figure shows the pipe fitting assembly.

The disappointment of wind turbine gearboxes might be followed to the irregular blasting nature of the breeze. Indeed, even the littlest whirlwind will make an uneven stacking on the rotor edges, which will create a torque on the rotor shaft that will unevenly stack the orientation and skew the teeth of the riggings.

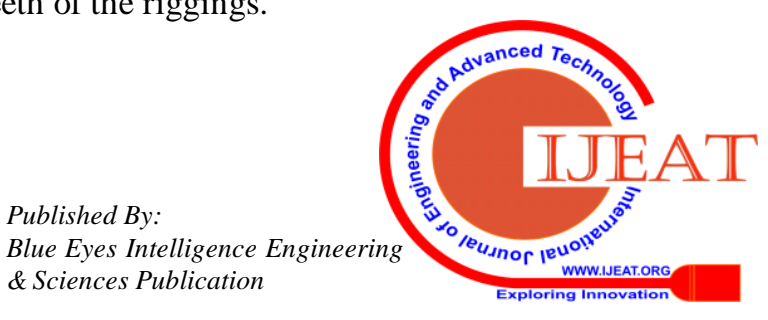


This misalignment of the riggings brings about uneven wear on the teeth, which thus will encourage further misalignment, which will cause progressively uneven wear, etc in a positive input way. The machine suspension will move, which will skew the gearbox with the generator shaft and may in the long run reason a disappointment in the fast back equipping bit of the gearbox.

Further aggravating the issue of uneven rotor cutting edge stacking is the blast cutting impact, which alludes to various edges more than once going through a limited blast (Burton et al.,2004). In the event that a whirlwind were to require 12 seconds to go through the cleared region of a breeze turbine rotor working at $15 \mathrm{rpm}$, every one of the three sharp edges would be dependent upon the blast multiple times, bringing about the gearbox being exposed to an aggregate of nine uneven loadings in a quick progression.

Most of gearboxes at the 1.5 MW appraised power scope of wind turbines utilize an a couple of stage planetary outfitting framework, in some cases alluded to as an epicyclical equipping framework. In this course of action, various external apparatuses, planets, spin around a solitary focus gear, the sun. So as to accomplish an adjustment in the rpm, an external ring or annulus is required.

Planetary equipping frameworks display higher power densities than parallel hub outfits, and can offer a huge number of outfitting choices, and an enormous change in rpm inside a little volume. The drawbacks of planetary equipping frameworks incorporate the requirement for profoundly complex structures, the general unavailability of indispensable parts, and high stacks on the pole heading. It is the remainder of these three that has demonstrated the most inconvenient in wind turbine applications.

As per contemplates, gearbox disappointments record to 5 percent of wind turbine disappointments. In any case, they are expensive contrasted and different disappointments when they happen[19],[21],[22].

Among the gearbox related disappointments larger part of the issues can be identified with grease arrangement of the gearbox. Beneath grievances were gotten from field in the earlier years concerning grease framework:

Distinctive material blend of ferrules and cylinders are utilized in wind turbine gearbox grease frameworks.

Tempered steel (SS)

Carbon steel (CS)

Hardness worth varies for every material. We have performed various tests to recognize the condition of ferrule pre-set in each combination.

\section{CONCLUSION}

From the available test results it can be concluded that:

Combination of the similar materials like stainless steel pipe \& Stainless steel ferrule, carbon steel pipe \& carbon steel ferrule having the good crimping and excellent pull out force. Which also means that the difference within the combination of materials is not allowing proper crimping and leads to the leakage.

\section{REFERENCES}

1. Tatikonda, N.C. \& Naveenchandran, P. 2019, "The behaviour of a compression ignition engine under the influence of diesel and microalgae biodiesel blends", International Journal of Mechanical and Production Engineering Research and Development, vol. 9, no. 4, pp. 447-456.

2. Tatikonda, N.C. \& Naveenchandran, P. 2019, "An experimental assessment on the impact of injection pressure on the characteristics of a diesel engine powered with the blend of diesel and microalgae biodiesel", International Journal of Engineering and Advanced Technology, vol. 8, no. 6, pp. 3284-3291.

3. Karthikeyan, S., Raman Balasubramanian, S.R., Ramesh, B., Raghul, S. \& Sathish Kumar, S. 2019, "The automatic solar tracker chronicles", International Journal of Recent Technology and Engineering, vol. 8, no. 1, pp. 312-315.

4. Hema, R., Sundararajan, M. \& Balaji, S. 2019, "Smartphone control robot with automatic firing gun", International Journal of Innovative Technology and Exploring Engineering, vol. 8, no. 9 Special Issue 3, pp. 625-627

5. Saritha, B., Chockalingam, M.P. \& Aswathy, M. 2019, "Degradation of anionic dye using Fe/Tio2 composite by photocatalysis", International Journal of Innovative Technology and Exploring Engineering, vol. 8, no. 9 Special Issue 3, pp. 788-791.

6. Saritha, B., Maria Subashini, L. \& Aswathy, M. 2019, "Utilization of spent coffee grounds for compost production", International Journal of Innovative Technology and Exploring Engineering, vol. 8, no. 9 Special Issue 3, pp. 908-910.

7. Fernando, J.K., Meikandaan, T.P. \& Hemapriya, M. 2019, "Better utilisation of bottom ash in coal fired thermal power station", International Journal of Innovative Technology and Exploring Engineering, vol. 8, no. 9 Special Issue 3, pp. 898-900.

8. Kumar, K.S., Kiruthiga, K. \& Thendral, S. 2019, "Experimental analysis on fractional substitution of bond by utilizing rice husk cinder", International Journal of Innovative Technology and Exploring Engineering, vol. 8, no. 9 Special Issue 3, pp. 1163-1165.

9. Vignesh, P., Madan, P., Mohankumar, D. \& Naveenchandran, P. 2019, "Optimization of four stroke c.i. engine performance by using statistical techniques (mathematical method)", International Journal of Recent Technology and Engineering, vol. 8, no. 2, pp. 1685-1691.

10. Bharanidharan, S., Sathiyamurthy, K. \& Sheeba, B. 2019, "Using co-precipitation method determining synthesis and characterization of fe doped zinc oxide nanoparticles", International Journal of Innovative Technology and Exploring Engineering, vol. 8, no. 9 Special Issue 3, pp. 705-707.

11. Jeevanandan, D. \& Vino, J.A. 2019, "Heat recovery from boiler blowdown water by using heat exchanger in thermal power plant", International Journal of Mechanical and Production Engineering Research and Development, vol. 9, no. 3, pp. 219-222.

12. Rakesh, N.L., Balambica, V. \& Kannan, S. 2019, "Biogas extraction from waste orange peel by digestion process", International Journal of Mechanical and Production Engineering Research and Development, vol. 9, no. 3, pp. 323-330.

13. Meenakshi, C.M. \& Krishnamoorthy, A. 2019, "The mechanical characterization of mono and hybrid fiber reinforced composites using experimental and finite element analysis methods", International Journal of Mechanical and Production Engineering Research and Development, vol. 9, no. 3, pp. 189-196.

14. Mohankumar, D., Prem Jayakumar, M., Sabarsish, R. \& Naveen Chandran, P. 2019, "Modeling and experimental investigation on centrifugal blower by computational fluid dynamics", International Journal of Mechanical and Production Engineering Research and Development, vol. 9, no. 3, pp. 331-340.

15. Balambica, V., Deepak, V. \& Kumar, S. 2019, "Design and efficiency of an asymmetric gear", International Journal of Mechanical and Production Engineering Research and Development, vol. 9, no. 3, pp. 223-230.

16. Manavalan, S., Balakrishnan, G. \& Ramasubramaniam, S. 2019, "An effect of cobalt oxide nano additive with biodiesel blends using cidi diesel engine", International Journal of Mechanical and Production Engineering Research and Development, vol. 9, no. 3, pp. 211-218. 
17. Golden Renjith Nimal, R.J., Sivakumar, M. \& Esakkimuthu, G. 2019 , "An investigation on mechanical properties and microstructure of mg/al alloys using zn interlayer during diffusion bonding", International Journal of Mechanical and Production Engineering Research and Development, vol. 9, no. 3, pp. 125-130.

18. Hariharan, R., Raja, R. \& Vasu, S. 2019, "Mechanical and tribological behaviour of thin tan coating produced on AISI 1018 substrate by DC magnetron sputtering", International Journal of Recent Technology and Engineering, vol. 7, no. 6, pp. 591-598

19. Manavalan, S., Rai, R., Kumar, R.R., Chaudhary, R.K. \& Chaudhary, S.K. 2019, "Impact of modified piston - A review", International Journa of Recent Technology and Engineering, vol. 8, no. 6, pp. 616-620.

20. Manavalan, S., Gopi, A., Arivarasu, J., Abishek Ahi, A. \& Chandru, S. 2019, "Review on ceramic disc brake system", International Journal of Recent Technology and Engineering, vol. 7, no. 6, pp. 612-615.

21. Sabarish, R. \& Jeya Kumar, M.P. 2019, "The design and analysis of piston - Steady state thermal analysis using "ansys"", International Journal of Mechanical and Production Engineering Research and Development, vol. 9, no. 3, pp. 197-204.

22. Ravi, D. 2019, "CFD simulation of solar loading in car", International Journal of Mechanical and Production Engineering Research and Development, vol. 9, no. 3, pp. 231-236.

\section{AUTHORS PROFILE}

S. Thirumavalavan Assistant Professor, Department of Mechanical Engineering, Bharath Institute of Higher Education and Research, Chennai, India.

Sabarish R Assistant Professor, Department of Mechanical Engineering, Bharath Institute of Higher Education and Research, Chennai, India.

Karthikeyan S Assistant Professor, Department of Mechanical Engineering, Bharath Institute of Higher Education and Research, Chennai, India. 